\title{
EXPERIÊNCIAS NO ESTÁGIO SUPERVISIONADO NA EJA EM TEMPOS DE PANDEMIA: PERCURSO E REFLEXÕES SOBRE A FORMAÇÃO DOCENTE
}

\author{
EXPERIENCES IN THE SUPERVISED INTERNSHIP IN EJA IN PANDEMIC TIMES: ROUTE AND \\ REFLECTIONS ON TEACHING TRAINING
}

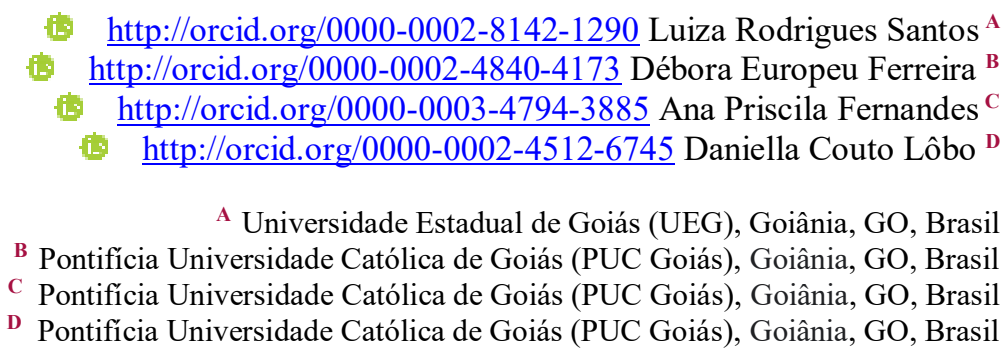

Recebido em: 19 ago. 2020 | Aceito em: 16 ago. 2021 Correspondência: Luiza Santos (rosantos.luiza@gmail.com)

\begin{abstract}
Resumo
O presente artigo se circunscreve à apreensão de como se deu a experiência de Estágio Supervisionado III e IV do curso de Pedagogia da PUC Goiás. Considera os reflexos da pandemia da Covid-19 e tem por objetivo geral apresentar reflexões sobre a experiência do Estágio Supervisionado na Educação de Jovens e Adultos (EJA). É fundamentado por pesquisa bibliográfica, cujos principais autores são: Pimenta e Lima (2004), Arroyo (2007), Libâneo (2001; 2010) e Freire (2017). Este estudo evidenciou que pensar educação para adolescentes, jovens, adultos e idosos, requer romper com muitos estigmas e estereótipos cristalizados ao longo do tempo. É importante reconhecer que o ambiente dessa modalidade de ensino é marcado pela diversidade e interação entre diferentes grupos etários, o que permite diálogo entre os diversos saberes construídos por meio das vivências e experiências. Ademais, se o acesso e permanência aos espaços escolares para esses indivíduos têm sido demarcado historicamente pelas desigualdades sociais, tal cenário tem se intensificado durante o período de aulas remotas.
\end{abstract}

Palavras-chave: Educação de Jovens e Adultos; Estágio; Pandemia.

\begin{abstract}
The present article circumscribed to the apprehension of how the experience of Supervised Internship III and IV of the Pedagogy course of the PUC Goiás carried out. It considers the reflections of the Covid-19 pandemic and its general objective is to present reflections about the experience of the Supervised Internship in Youth and Adult Education (YAE). It is based on bibliographic research, whose main authors are: Pimenta and Lima (2004), Arroyo (2007), Libâneo $(2001 ; 2010)$ and Freire (2017). This study showed that thinking about education for adolescents, youth, adults, and the elderly requires breaking with many stigmas and stereotypes crystallized over time. It is important to recognize that the environment of this type of education marked by diversity and interaction between different age groups, which allows dialogue between the various knowledge built through experiences. Furthermore, if the access and permanence to school spaces for these individuals been historically demarcated by social inequalities, such scenario has intensified during the period of remote classes.
\end{abstract}

Keywords: Youth and Adult Education; Internship; Pandemic.

\section{(1) 3}

2021 Santos; Ferreira; Fernandes; Lôbo. Este é um artigo de acesso aberto distribuído sob os termos da Licença Creative Commons Atribuição Não Comercial-Compartilha Igual (CC BY-NC-4.0), que permite uso, distribuição e reprodução para fins não comercias, com a citação dos autores e da fonte original e sob a mesma licença. 


\section{Introdução}

Somente uma escola centrada democraticamente no seu educando e na sua comunidade local, vivendo as suas circunstâncias, integrada com os problemas, levará os seus estudantes a uma nova postura diante dos problemas de contexto. À intimidade com eles.

Paulo Freire

O presente artigo, intitulado "Experiências no Estágio Supervisionado na EJA em tempos de pandemia: percurso e reflexões sobre a formação docente", se circunscreve à apreensão de como se deu a experiência de Estágio Supervisionado III e IV, realizado no âmbito da Educação de Jovens e Adultos (EJA) do curso de Pedagogia da PUC Goiás, compreendendo o período de um ano (2019/2 - 2020/1), no qual foi possível considerar os reflexos iniciais da pandemia da Covid-19. O objetivo geral foi apresentar reflexões sobre a experiência de Estágio Supervisionado na EJA e apontar as contradições encontradas com base no cenário atual. Visouse, enquanto objetivos específicos, fazer apontamentos sobre o Estágio Supervisionado da PUC Goiás, apresentar as vivências no Estágio, as vicissitudes do cenário pandêmico e discutir sobre os desafios da docência na EJA.

Este estudo fundamentou-se em pesquisa bibliográfica direcionada para referências já analisadas e publicadas como, por exemplo, livros, artigos, revistas e sites, por compreender que este tipo de análise contribui de forma singular para a análise e compreensão do estágio enquanto campo de pesquisa. Neste sentido, os principais autores que contribuíram com estas reflexões foram: Pimenta e Lima (2004), Arroyo (2007), Libâneo (2001; 2010) e Freire (2017).

Na primeira seção, que tem por título "Estágio supervisionado na PUC Goiás: alguns apontamentos", faz-se uma discussão acerca das concepções de estágio admitidas pelas Diretrizes de Estágio Supervisionado da referida universidade que norteiam as perspectivas teóricas e práticas dessa disciplina. São destacados, também, os fundamentos pedagógicos, etimológicos e sociopolíticos, de modo a materializar a educação como prática social necessária à formação pedagógica.

$\mathrm{Na}$ segunda seção, intitulada "As vivências no Estágio", versa-se acerca das expectativas referentes à EJA e que se confirmaram como questões que foram suprimidas pela pandemia da Covid-19, causando prejuízos para a formação docente no que tange à relação teoria-prática-teoria, condição fundante para o exercício da profissionalidade das discentes/estagiárias do curso de Pedagogia. Além disso, pôde-se verificar que a pandemia intensificou a desigualdade social na EJA e na educação, de modo geral e em sua vasta extensão, 
de tal maneira que os processos de mediação e aprendizagem passaram a ocorrer de forma contraproducente.

Por fim, a terceira seção, "Os desafios da docência na Educação de Jovens e Adultos: reflexões”, traz algumas considerações sobre quem são os sujeitos da EJA, destacando suas origens como trabalhadores em diferentes faixas etárias, pessoas que possuem histórias de vida e expectativas de futuro, assim como necessidades e sonhos a serem alcançados e que, além disso, são sujeitos que participam de grupos e lutas sociais diversas. Ainda nesta seara, este estudo questiona qual a formação adequada aos docentes da EJA que viria a contribuir para que seus educadores possam propiciar caminhos que favoreçam uma educação como prática transformadora aos jovens e adultos.

\section{Estágio Supervisionado na PUC Goiás: alguns apontamentos}

“Pedagogia e Pedagogos, para quê?” é uma das obras de José Carlos Libâneo (2010), livro que busca conferir sentido às observâncias intrínsecas à condição do campo científico da Pedagogia. Entendendo o título como provocação, levanta-se ponto importante a ser pensado e discutido: Estágio na Pedagogia, para quê? Nessa lógica, necessário se faz raciocinar para além do campo da Pedagogia de modo a contemplar o tempo e o espaço em que se insere o questionamento.

O Estágio, assim como a Educação e a Pedagogia, possui diferentes concepções construídas ao longo da história de acordo com Libâneo (2010). Tais formas de perceber o significado do Estágio se inserem em modos de compreender e atuar sobre o mundo, assim como a necessidade de inteirar-se de quais perspectivas, anseios, intenções políticas, éticas, sociais e morais conformam o saber, considerando que a compreensão de conceitos tão importantes como a Educação, a Pedagogia e a relação com o próprio Estágio são indissociáveis. O autor, em sua construção sobre o percurso e a identidade profissional do pedagogo, levanta questões importantes que dizem respeito ao ato educativo como atividade humana intencional e prática social.

Ainda em conformidade com Libâneo (2010) o trabalho docente tem caráter pedagógico devido à sua intencionalidade, pautada em objetivos explícitos. Diante disso, as Diretrizes do Estágio Supervisionado no Curso de Pedagogia da PUC Goiás (2014) levam em consideração, sobretudo, as contribuições de Libâneo, com a finalidade de explicitar os objetivos que pautam a concepção de Estágio creditada pela instituição.

De acordo com as Diretrizes citadas acima, o Estágio Supervisionado Obrigatório da PUC Goiás se configura como uma disciplina curricular do curso de Pedagogia que visa 
proporcionar experiências formativas para os graduandos, para que possam apropriar-se dos conhecimentos inerentes à docência. De modo geral, inicialmente, os graduandos fazem a observação-participante no campo de Estágio. Depois, realizam uma análise crítica e a reflexão teórica por meio dos diários de campo e, posteriormente, a elaboração e execução do Projeto de Estudo, Investigação e Mediação Pedagógica. A partir disso, as experiências em sala de aula são socializadas no contexto acadêmico sob a mediação dos professores da Universidade (PUC GOIÁS, 2014).

O Estágio em questão é compreendido como uma atividade alicerçada na teoria-práticateoria que possibilita um contato direto com o campo de trabalho, uma forma de vivenciar as possibilidades dentro de uma sala de aula. Desta feita, os graduandos têm a oportunidade de exercer a práxis, experimentando o exercício da docência na Educação Infantil, no Ensino Fundamental, na Educação de Jovens e Adultos e em espaços de educação não formais. Conforme as Diretrizes do Estágio Supervisionado no Curso de Pedagogia da PUC Goiás (2014):

Compreende-se à docência como ação educativa, um processo pedagógico metódico e intencional, permeado pelas relações sociais, étnico-raciais e produtivas, as quais influenciam conceitos, princípios e objetivos da Pedagogia, desenvolvendo-se na articulação entre conhecimentos científicos e culturais, valores éticos e estéticos inerentes a processos de aprendizagem, de socialização e de construção do conhecimento, no âmbito do diálogo entre diferentes visões de mundo (PUC GOIÁS, 2014, p. 12).

Considerando a docência enquanto ação educativa, o Estágio Supervisionado contribui para a formação humana dos graduandos, pois, é um momento de possibilidades, de construções, de análises acerca do papel do educador e da instituição de ensino. Experiência que amplia os conhecimentos teóricos já adquiridos, despertando curiosidades para a construção de novos saberes, constituindo-se como intenção efetiva a práxis nos aspectos político, ético e social. Sendo assim, a educação é tida como prática social, como sugerem as Diretrizes do Estágio Supervisionado:

Parte-se do princípio de que a educação é uma prática social constitutiva e constituinte entendida como processo histórico de relações humanas, situadas em espaços sociais em que ocorrem diferentes práticas educativas. Neste sentido, compreende-se o conhecimento produzido na e pela educação como constructo social de todos os sujeitos que compõem o fazer educativo. Na formação de professores, a construção do conhecimento se dá na e pela práxis, que incorpora as experiências vividas, compromissos éticos, políticos, as representações construídas nas interações e nos significados compartilhados pelas pessoas. Este pressuposto é importante uma vez que a formação de professores ocorre com base na universalidade do conhecimento é alicerçada numa sólida base humanística, ética e democrática (PUC GOIÁS, 2014, p. 14). 
A PUC Goiás, nos cursos de licenciatura, opta por realizar o Estágio Supervisionado em instituições públicas de ensino, pois acredita que "[...] uma das funções da Universidade é voltar-se para o bem público, a fim de defendê-lo e qualificá-lo, já que sua natureza é pública, portanto, bem comum, universal, para todos" (PUC GOIÁS, 2014, p. 15). Neste contexto, o Estágio Supervisionado da PUC Goiás busca consolidar a autonomia e a autoria intelectual dos acadêmicos e docentes, a partir dos seguintes eixos: adoção de uma postura investigativa; produção de roteiros de observação e análise; reflexão teórica com base na problematização; mudança no foco do Estágio - da atitude passiva/contemplativa para ativa/propositiva; e, adoção de postura intelectual (PUC GOIÁS, 2014).

Levando em consideração os eixos centrais para a formação docente, o Estágio se configura como a concretização da participação e intervenção na sociedade, isto é, consiste em prática política aliada ao compromisso ético na transformação social e profissional. Vale ressaltar que, segundo as Diretrizes já citadas:

[...] faz-se necessário compreender que o estágio não é apenas atividade prática, mas também, teórica que qualifica a ação docente numa perspectiva que pode ser entendida como atividade transformadora da realidade. Portanto, o estágio é atividade teórica de conhecimento, diálogo e intervenção (PUC GOIÁS, 2014, p. 11).

Diante disso, Pimenta e Lima (2004), ao tratarem sobre as diferentes concepções de Estágio, rememoram a prática como imitação de modelos e instrumentalização técnica. A primeira possui fundamento no modo tradicional da ação docente e reduz o Estágio à mera observação e imitação. A segunda se refere à técnica, sendo o campo de Estágio o local de reproduzi-la. Na perspectiva dos autores supracitados, em concordância e referenciada pelas Diretrizes do Estágio Supervisionado no Curso de Pedagogia da PUC Goiás (2014), o Estágio está para além da prática isolada, sendo, portanto, o diálogo entre a teoria e a prática.

O Estágio consiste no entendimento do educador enquanto profissional que exerce uma prática social, isto é, que tem por finalidade intervir na realidade por meio das instituições que promovem a educação. Neste sentido, o Estágio se estabelece como uma forma de o futuro docente aproximar-se dessa realidade e refletir sobre ela, contribuindo para a identificação dos limites da prática educativa e colaborando na criação de condições para superá-los (PIMENTA; LIMA, 2004).

A Pedagogia contempla um conceito ampliado do significado da Educação que se compromete com a transformação social e entende a realidade como algo que está em constante movimento. Para isso, a Pedagogia se apropria do lugar que realiza pesquisa, investigação e práxis, sendo sempre intencional. 
Assim como discute Libâneo (2010, p. 30), a Pedagogia é “o campo do conhecimento que se ocupa do estudo sistemático da educação, isto é, do ato educativo, da prática educativa concreta que se realiza na sociedade como um dos ingredientes básicos da configuração da atividade humana". Ao refletir e pesquisar sobre as ações pedagógicas e como elas têm se constituído no âmbito escolar é importante compreender a importância de estabelecer ligação entre teoria e prática, não as tratando de forma isolada.

\begin{abstract}
Nesse processo [de reflexão nas e das ações pedagógicas], o papel das teorias é iluminar e oferecer instrumentos e esquemas para análise e investigação que permitam questionar as práticas institucionalizadas e as ações dos sujeitos e, ao mesmo tempo, colocar elas próprias em questionamento, uma vez que as teorias são explicações sempre provisórias da realidade (PIMENTA; LIMA, 2004, p. 43).
\end{abstract}

Diante do cenário atual, marcado pela pandemia da Covid-19, o Estágio Supervisionado que integra a matriz curricular do curso de Pedagogia da PUC Goiás foi realizado de forma remota em 2020/1. Vale considerar que as aulas do Regime Letivo Remoto Extraordinário aderido pela PUC Goiás, em conformidade com as orientações das autoridades sanitárias por meio da Portaria n. ${ }^{\circ}$ 11/2020, que deu início ao Regime, estabeleceu que as aulas fossem realizadas por meio do Ambiente Virtual de Aprendizagem (AVA) - (PUC GOIÁS, 2020).

Neste contexto, foram utilizados dois ambientes: o Moodle e o Teams. O Moodle, plataforma própria da Universidade, foi utilizado para postagem de atividades e para estabelecer o primeiro contato virtual por meio do chat. Já o Teams, que é uma plataforma da Microsoft, foi utilizado para a realização de videoconferências no mesmo horário das aulas presenciais, seguindo o Plano de Ensino adaptado de acordo com as condições do cenário pandêmico.

As escolas-campo que têm por característica serem instituições públicas, como dito anteriormente, tiveram que suspender as aulas presenciais e readaptar suas atividades, enquanto as de cunho privado permaneceram com suas atividades de forma remota. Diante disso, as idas ao campo de Estágio e o cumprimento com os requisitos formais previstos nas orientações do Estágio foram impossibilitados, por se tratar de um momento de exceção.

Precedente ao distanciamento social, as estudantes/estagiárias de Pedagogia, como fruto da observação in loco das aulas e por meio dos estudos e do exercício reflexivo, planejaram e sistematizaram suas intervenções que culminaram no Projeto de Estudo, Investigação e Mediação Pedagógica, documento que será discutido na seção seguinte desta análise. De forma a consolidar e subsidiar os planos de ensino, utilizou-se como metodologia para o desenvolvimento e mediação das regências diversos gêneros textuais (receitas, músicas, poesias, jornais, etc.). Tais escolhas foram feitas com a finalidade de estudar as raízes goianas, a história de Goiás, a economia e produção do estado, as suas principais cidades e o bioma 
Cerrado. Entretanto, é importante considerar que devido ao distanciamento social, as atividades do Projeto não foram realizadas conforme o programado.

\section{As Vivências no Estágio Supervisionado}

Quando se inicia uma nova experiência é normal sentir receios e inseguranças. Na EJA, sob o ponto de vista do estágio não seria diferente, pois, ainda que represente uma experiência extraordinária, o "começar" pode gerar espanto. Trata-se de um contexto no qual estão presentes histórias, traumas, e demandas que, além de sociais, são históricas. Por isso, ao surgir a necessidade de levantar um tema que viesse a contribuir com os educandos de modo a valorizar as diferentes identidades por meio de um projeto de mediação pedagógica foi identificado grande desafio à frente.

Vivenciar o Estágio consiste, sobretudo, perceber os mínimos detalhes na convivência com entre docentes e discentes, de maneira a compreender que cada um dos sujeitos inseridos em sala é constituído de história e fazem história no decorrer da vida. E é justamente pensando no ser e fazer história, que o projeto intitulado "Perspectivas e conhecimentos sobre as raízes goianas" foi elaborado. O referido projeto foi formulado como parte do processo de formação docente, assim como propõe as Diretrizes do Estágio Supervisionado, mas, também, de forma a contribuir com os educandos da escola-campo.

A problemática surgiu a partir da experiência de observação em sala de aula, na qual foi possível perceber algumas questões referentes ao perfil dos alunos, idades, aspirações, histórias de vida, subjetividades, saberes e conhecimentos necessários para a realização do trabalho na EJA.

O grupo em questão estava matriculado na turma do $5 .^{\circ}$ ano, com especificidade etária diversificada, correspondendo a idades que variavam entre 15 e 60 anos, sendo majoritária a presença de adultos, enquanto havia um número menor de jovens e adolescentes. Contou-se com, aproximadamente, 7 estudantes frequentes ( 2 mulheres e 5 homens). Tal perfil denota que ao pensar sobre a EJA está a preocupação em considerar, de modo apropriado, esta modalidade de educação que acolhe os sujeitos em seus contextos, os quais são caracterizados pela desigualdade social, própria de um modelo de organização econômico-social capitalista, o que evidencia a necessidade e urgência desses sujeitos de vivenciarem processos de aprendizagem em um contexto crítico e emancipatório.

Segundo a Proposta Político Pedagógica da Educação de Adolescentes, Jovens e Adultos (GOIÂNIA, 2013), os sujeitos que necessitam da EJA, em sua maioria, fazem parte da classe trabalhadora, se dedicam a trabalhos informais e, de modo geral, não possuem 
qualificação e vivem de trabalhos temporários. Fazem parte também desse perfil de estudantes da EJA as donas de casa, mães e avós. Majoritariamente, são pessoas que trabalham como empregados domésticos, pedreiros, serventes e outros atuam no setor de serviços e manutenção. Outro fato pontuado pela proposta é a origem desses alunos, os idosos e adultos são migrantes da zona rural do interior de Goiás, da região norte e nordeste. Os adolescentes e jovens estão ligados à cultura urbana, possuem idade inferior a 25 anos e detêm uma trajetória escolar marcada por descontinuidades, exclusão social e conflitos com seus familiares (GOIÂNIA, 2013).

Estes dados exigem de todos os profissionais envolvidos no processo educativo, reavaliar a práxis e o currículo, no sentido de proporcionar reflexões quanto aos conhecimentos adquiridos pelos educandos e o seu lugar de protagonismo, uma vez que a atenção deve ser voltada sempre para eles e suas necessidades de aprendizagem e interações. Deve-se lembrar que na EJA as condições biológicas infantilizadas dos sujeitos já foram superadas, por isso carregam consigo um capital cultural e experiências de vida que devem ser ouvidas, respeitadas e valorizadas, ou seja, percebidas como conhecimentos prévios. Estes aspectos devem ser reconhecidos como ponto de partida pelo educador que possibilitem a compreensão do processo político, econômico e social no qual esses discentes se encontram, com vistas a transformá-lo; ademais, devem, ainda, favorecer a apreensão dos conhecimentos formais e contribuir com o processo pedagógico.

Com base no exposto, evidenciou-se a necessidade de trabalhar com os educandos de forma significativa, proporcionando espaços e momentos de autonomia e voz, visto que as observações feitas no estágio não identificaram momentos de debates e interações entre as partes. De modo que priorizou-se preparar algo que trouxesse integração e participação ativa, com a intenção de instigar os estudantes ao questionamento, à reflexão e à percepção de si mesmos como parte integrante do processo educacional.

O objetivo do projeto de mediação pedagógica do estágio ora explicitado é conhecer as perspectivas e os conhecimentos sobre as raízes goianas por meio de uma educação como prática libertadora, que, em concordância com Freire (2017), entende as pessoas como agentes que operam e transformam o mundo. Considerou-se, ainda, a importância de situar o educando como sujeito do processo histórico, desenvolver o senso de participação, os valores e as interações sociais, além de valorizar a cultura goiana, sua identidade e diversidade.

Para nortear o desenvolvimento do projeto, levantou-se os questionamentos a seguir: Por que conhecer as raízes goianas? Por que trabalhar com perspectivas e conhecimentos? Levou-se em consideração conhecer, compartilhar e valorizar a história do estado de Goiás para 
além de datas e acontecimentos isolados, ou seja, com o intuito de possibilitar o reconhecimento do sujeito enquanto agente social de transformação, além de proporcionar a criticidade, o respeito à diversidade e à leitura de um mundo plural em constante mudança.

Embora a oportunidade de mediar os planos de aulas tenha sido negada, devido a pandemia da Covid-19, foram realizados estudos de textos complementares na disciplina de Estágio Supervisionado, além da exposição e discussão dos projetos elaborados pela turma. Durante as aulas remotas as leituras realizadas proporcionaram o contato com práticas já efetivadas, a fim de que fosse possível ponderar sobre elas no que se refere à realidade cotidiana da EJA no campo teórico e de modo a construir conhecimentos acerca do sujeito que ocupa esse espaço, assim como recomenda a Proposta Político-Pedagógica da Educação de Adolescentes, Jovens e Adultos, da Secretaria Municipal de Educação e Esporte de Goiânia:

\begin{abstract}
Pensar em adolescentes, jovens, adultos e idosos como educandos requer romper com cristalizações sociais impostas às idades da vida que separam os seres adultos dos seres em formação; implica, ainda, pensar esses sujeitos em processos de ensino e aprendizagem marcados pela diversidade e pela interação entre diferentes grupos etários. Como tempo e espaço de relações intergeracionais, de diálogo entre saberes, de compreensão e de reconhecimento da experiência e da sabedoria, tensionadas pelas culturas dos diferentes sujeitos. Estas, muitas vezes são tratadas na EAJA como conflitos, como problemas (GOIÂNIA, 2013, p. 21).
\end{abstract}

Desta forma foi possível ampliar o olhar em relação ao sujeito da EJA e no que tange à instituição de ensino, pois a escola deve ser um lugar de acolhimento, onde os educandos se sintam seguros para obterem sua formação e desenvolvimento, consolidando um espaço de igualdades que não perpetue o olhar de marginalização. Conforme aborda Arroyo (2007), os sujeitos da EJA são estereotipados como alunos evadidos, reprovados, defasados, com problemas de frequência e de aprendizagem, porém, esses estudantes foram excluídos dos saberes que a escolarização deveria garantir.

Quanto ao aspecto metodológico e cronológico, o Estágio Supervisionado se deu da seguinte forma: no primeiro semestre as estagiárias do sétimo período do curso de Pedagogia exerceram o papel de observadoras-participantes, além de realizarem estudos sobre a EJA e elaborar um projeto de mediação pedagógica. Já o segundo semestre foi iniciado com muitas expectativas para a execução do projeto, momento no qual foi feita mais uma visita ao campo, culminando na elaboração dos planos de aula. Porém, antes mesmo de serem realizados, houve o anúncio de que seria inevitável o distanciamento social ${ }^{\mathrm{i}}$ como forma de evitar a propagação do novo coronavírus.

O planejamento das aulas foi realizado para que as mesmas acontecessem em uma escola municipal de Goiânia, onde as alunas de Pedagogia iniciaram o estágio, no segundo 
semestre de 2019, e onde dariam continuidade ao trabalho no primeiro semestre de 2020 . Entretanto, as condições não favoreceram a efetivação e mediação do projeto elaborado para o 5. ${ }^{\circ}$ ano da EJA. A princípio havia esperanças de retorno às aulas presenciais e cumprimento do planejamento. No entanto, como as condições foram contrárias, as intervenções do estágio concentraram-se na produção das atividades acadêmicas (relatórios, fichamentos e resenhas dos textos estudados) e na elaboração do Relatório Final do Estágio IV, conforme roteiro, orientações e cronogramas pré-definidos pela professora de estágio.

Devido a conjuntura atual de distanciamento social, seguidos lockdowns e o não retorno das aulas presenciais (fator importante no enfrentamento da Covid-19), constatou-se prejuízo à formação docente. No campo da Pedagogia, propiciar uma formação presencial e participativa para os futuros docentes significa compreender a relação indissociável entre teoria-práticateoria, amplamente apoiadas pelas Diretrizes de Estágio da PUC Goiás, uma vez que devem ser marcadas pela observação, análise crítica, reflexão teórica, mediação pedagógica, sistematização documental dos processos ocorridos no cotidiano da sala de aula, na socialização das experiências favorecidas pelas vivências e na relação construída pela práxis educativa, garantindo, desse modo, a solidificação da experiência formativa.

No aspecto investigativo estão as ações empreendidas pelos acadêmicos nas quais devem buscar, refletir, discutir, registrar e socializar com os seus pares, concebendo o ensino conforme Libâneo (2001), como atividade reflexiva. A garantia dessa premissa está no contexto do Estágio Supervisionado que intensifica a formação docente como condição substancial para o exercício da profissionalidade, quando o estagiário passa de um estado ativo/contemplativo para ativo/propositivo, o que se torna possível a partir das regências, do cumprimento e da mediação dos planos de aulas elaborados por meio de uma abordagem crítica-intelectual, que possibilita, ainda, a apreensão dos fenômenos educativos e os posiciona no campo das relações sociais.

\section{Desafios da Docência na Educação de Jovens e Adultos}

Considerar as particularidades e subjetividades historicamente constituídas pela EJA configura-se como eixo central da docência nessa modalidade de ensino. Uma das particularidades do trabalho na EJA é a multiplicidade que se constrói em termos de organização metodológica e curricular, perspectiva que possibilita lidar com os diferentes ritmos de aprendizagem e com as diferenças de apropriação do conhecimento dos alunos. Nesse 
aspecto a EJA exige uma discussão mais ampla a iniciar pela contextualização de sua definição. Nas palavras de Paiva (1973, p. 16), A educação de jovens e adultos é toda educação destinada àqueles que não tiveram oportunidades educacionais em idade própria ou que tiveram de forma insuficiente, não conseguindo alfabetizar-se e obter os conhecimentos básicos necessários.

O sujeito jovem/adulto, ao ter convivido com uma noção de fracasso na sua relação escolar e percebê-la como uma falta sua, visualiza uma concepção de escola identificada como aquela que o excluiu e à qual não atribui significação positiva. Além disso, nessa relação truncada que estabelece com o saber, constrói uma imagem desvalorizada de si, concepção construída em sua relação escolar com o saber valorizado socialmente. Desse modo, essa imagem não está no sujeito em si, mas se constrói na distância em que ele se percebe em relação a esse saber.

Ao retornar à escola o jovem/adulto busca ter acesso ao mundo letrado marcado pelo desejo de ler e escrever, uma vez que vive em uma sociedade que exige o uso da escrita e do conhecimento sistematizado. Neste sentido a idade adulta passa a ser percebida como uma possibilidade de aprender, na qual jovens e adultos, em sua maioria naturais das frações populares, trazem histórias análogas de vivências dentro das desigualdades sociais perante o mundo e a escola. São educandos que precisam ser compreendidos como sujeitos socioculturais, constituídos por percursos próprios de inserção no mundo. Esse olhar possibilita reconhecer tais sujeitos em seus tempos e percursos, com modos concretos de inserção e de ação no mundo social, em situações particulares de existência, como produtores de saberes e detentores do direito de participar dos bens culturais produzidos historicamente. Gadotti (2013, p. 14), em suas elucidações sobre a Educação de Adultos como Direito Humano, exemplifica bem as diversas particularidades desses discentes:

A Educação de Jovens e Adultos relaciona-se com vários temas, entre eles: a questão da pobreza e das desigualdades, a questão das ONGs, comunicação e informação, mudanças climáticas, migrações (refugiados e imigrantes em situação 'irregular'), interculturalidade, empregabilidade e sobrevivência, economia solidária e, certamente, a educação como direito humano, como 'direito à educação emancipadora', como defende o Fórum Mundial de Educação.

Diante disso, é possível perceber as especificidades inerentes à condição dos alunos da EJA que, de forma perceptível, vão além da faixa etária por tratar-se também de questões relacionadas a trajetórias singulares. Sob essa ótica, é preciso entender que a modalidade de ensino em análise visa atender, prioritariamente, à classe trabalhadora e deve-se ter em vista 
que devido a fatores históricos e intrinsecamente ligados às políticas públicas, as mesmas têm sido colocadas à margem quando o assunto é educação formal.

A EJA não pode ser pensada de forma desarticulada das necessidades dos trabalhadoresestudantes, da identidade e particularidade de cada sujeito, do processo histórico constituído que culmina na negativa ao direito à escola, bem como da supressão de suas impressões e bagagens adquiridas nas interações sociais. É preciso, nessa perspectiva, compreender a necessidade de romper com a cultura assistencialista e excludente que ainda acompanha essa modalidade de ensino. Necessário se faz destacar, também, a importância da formação e da qualificação docente para atuar nas salas de aula da EJA, de acordo com as demandas e especificidades apresentadas pela área.

Os sujeitos da EJA são pessoas que trabalham para suprir suas necessidades e que buscam na escola os conhecimentos que possibilitem a melhoria de suas condições de vida e que não desejam fazer parte dos índices de evasão. Assim sendo, cabe aos educadores, juntamente com os educandos, entender as problemáticas que afastaram/afastam os sujeitos da escola na idade regular e desmistificar conceitos criados por eles a esse respeito, pois, se a educação ocorre ao longo da vida, toda idade é a certa para aprender (ROSA, 2017). Posto tais reflexões, a Proposta Político-Pedagógica da Educação de Adolescentes, Jovens e Adultos, também corrobora no sentido de compreender quais são os sujeitos dessa modalidade de ensino e o que os diferencia dos demais.

A EJA é uma modalidade de educação que acolhe os sujeitos em seus contextos, os quais são caracterizados pela desigualdade social, própria de um modelo de organização econômico-social capitalista. Isso evidencia a necessidade de se vivenciar os processos de aprendizagens e autoaprendizagens em um contexto crítico e político emancipatório, dando voz aos sujeitos adolescentes, jovens, adultos e idosos (GOIÂNIA, 2013, p. 19).

Refletir sobre os adolescentes, jovens, adultos e idosos em processo de aprendizagem escolar requer romper com muitos estigmas e estereótipos cristalizados ao longo do tempo. É importante reconhecer que o ambiente da modalidade EJA é marcado pela diversidade e interação entre diferentes grupos etários e que isso permite o diálogo entre os diferentes saberes construídos por meio das vivências e experiências que os estudantes já possuem e as que são oportunizadas por esta categoria de ensino.

Nessa percepção, as particularidades do processo de ensino-aprendizagem destacam-se como aspectos fundamentais ao modo como os educadores da EJA constroem alternativas para lidar com os diferentes níveis de conhecimento e ritmos de aprendizagem no espaço da aula. Essas alternativas ficam evidentes nas interações entre os professores e discentes durante o 
desenvolvimento em grupo e no instante em que os educadores apresentam as formas diversificadas de como tratar individualmente os educandos, assim como nas estratégias utilizadas ao proporem as aulas e definirem as atividades para a sua prática educativa.

A formação continuada dos professores, tais como: capacitação, especialização, formação permanente, atualização etc., se faz necessária nos contextos sociais e educativos, uma vez que se trata de uma profissão na qual é necessário aprender e reaprender por toda a vida, sendo este um de seus fundamentos de sua formação. Assim, compreendendo que os sujeitos são impregnados de eterna imperfeição e são inacabados/inconclusos e uma vez que os educadores são sujeitos jovens e adultos como seus alunos que também estão em processo de aprendizagem que persistirá por toda sua existência.

Destarte, o desafio aos educadores está em propor e transformar a formação em um caminho coletivo, mediando saberes, conhecimentos e práticas pedagógicas que os educadores desenvolvem individualmente, tornando-os repertório e patrimônio concreto, apoiados na possibilidade de um novo pensar acerca da modalidade EJA, para que ela se torne espaço de proposições que visem mudanças, com vistas a abandonar de vez a educação bancária. No entender de Paiva (2012, p.88):

Não se pode ignorar que a formação humana - campo de atuação da educação envolve não apenas o cuidado com o desenvolvimento de crianças e jovens e o aprendizado e aperfeiçoamento profissionais, mas também a ação específica no âmbito dos movimentos sociais, da vida cultural mais ampla, da participação política, enfim, de todo e qualquer tipo de atividade que tenha como finalidade a reflexão e a ação visando à instituição de novos modos de ser para os humanos e novas formas de coexistência entre eles. É o papel político da educação que deve ser ressaltado, e não sua forma escolar.

Dessa forma a educação deve ser concebida pela perspectiva do oprimido como prática libertadora tracejada por uma pedagogia problematizadora e crítica, na busca do "ser mais", com a possibilidade do sujeito encontrar sua humanidade junto com o outro e, assim, transformar-se em um ser humano melhor, problematizando o papel dos professores que também se humanizam enquanto aprendem e ensinam (FREIRE, 2017).

Ser professor da EJA exige uma docência coerente com as suas particularidades e uma postura de partilha da produção de referências, bem como o compromisso com uma ação politicamente consciente das dificuldades e dos limites que seu trabalho possui. Sendo assim, espera-se uma formação em nível superior e de formação continuada que contemplem tais particularidades e um campo de conhecimentos e saberes teórico-metodológicos sólidos que permitam refletir a EJA enquanto área de estudo fundamental. Sabe-se que a prática educativa é um desafio, pois o educador consciente se questiona, revê conceitos e busca contribuir de 
forma significativa na construção do conhecimento de maneira a propiciar ferramentas que cooperem com o intuito de favorecer a autonomia dos educandos.

Contudo, mesmo diante desses aspectos importantes, é notório como a EJA tem sido depreciada pelas políticas públicas, uma vez que o Estado a reconhece apenas como uma instância de formação para o trabalho, dedicando pouca importância à educação pós-idade escolar como um direito constitucional. É de amplo conhecimento que o Ensino Fundamental tem obtido mais atenção das políticas educacionais em prol da garantia da escolarização de crianças e adolescentes com idade de 7 a 14 anos, o que reafirma a necessidade de um olhar mais atento que gerem novos programas e projetos para a EJA. Para Arroyo (2007, p. 19), a Educação de Jovens e Adultos é campo ainda não consolidado no que diz respeito à pesquisa, às políticas públicas, às diretrizes educacionais, formação de professores e propostas pedagógicas, e por isso, há uma diversidade de tentativas de configurar sua especificidade.

Como reafirma a análise de Arroyo (2007), é possível perceber que ainda se tem muito que aprender com e sobre a EJA no que diz respeito ao que necessitam os educadores para um ensino direcionado e consciente, no sentido de conhecer a realidade dos educandos, suas culturas e expectativas, ao reexaminar a pedagogia para os jovens e adultos e adequá-la à realidade de seu público, bem como no que tange entender que o educando, em um espaço escolar, busca também por valores que extrapolam as questões puramente de ensino. Neste processo, evidencia-se a possibilidade de situar as particularidades das práticas educativas da EJA e fazer com que se revise a lógica da organização do sistema escolar "dito" regular, a procura de formas mais inclusivas e igualitárias de garantir seus direitos (ARROYO, 2007, p. 43-44).

Por meio de tal viés, faz-se urgente a discussão a respeito das políticas públicas educacionais em tempos de reformas fiscais (Emenda Constitucional n. ${ }^{\circ}$ 95) que consistem em cortes nos serviços públicos. Fundamentalmente, sobre o que está posto com relação à ineficácia da administração pública na educação e, também, com relação aos parcos investimentos dirigidos a esta área, apresentam-se sempre etéreos ou ineficientes para a educação popular. Contudo, é também neste contexto neoconservador que emergem os discursos que buscam retirar a autonomia das escolas e dos professores em sua ação docente.

\section{Considerações finais}

Diante da atual conjuntura, demarcada pela Pandemia da Covid-19, a disciplina de Estágio Supervisionado contribuiu para desmistificar inquietações inerentes à formação acadêmica e profissional, constituindo-se como campo de pesquisa. O intuito dessa disciplina 
é contribuir para o processo formativo dos graduandos, para que possam exercer a profissão docente, pautados na importância da relação teoria e prática, da criticidade, da pesquisa e da exploração dos conhecimentos construídos e dos que ainda estão em construção.

No contexto de aulas remotas da PUC Goiás, embora haja o reconhecimento de todo o esforço promovido pela instituição na tentativa de dirimir os efeitos prejudiciais quanto a lacuna das aulas presenciais, evidenciou-se que a "qualidade" no quesito "aprendizagem prática" que está diretamente vinculada à concepção de estágio na formação de professores foi prejudicada. Nesse sentido, há grande importância nos processos de mediação nas escolas-campo e por parte dos profissionais de docência na formação prática dos futuros professores, posto que os saberes necessários para a construção de uma atuação profissional do professor, além do próprio saber, numa dimensão mais teórica, requer que o discente de Pedagogia aprenda a fazer e a analisar esse saber fazer para que a sua prática pedagógica seja transformadora. Portanto, permanece o aspecto ativo/contemplativo, sem vistas ao ativo/propositivo.

Ainda assim, diante de tais percalços, o referido estágio na EJA reafirmou que cada sujeito é único, cada um tem histórias e memórias particulares. O sujeito é um agente social de transformação que, para além de ser e fazer cultura, contribui para uma leitura de mundo permeada pela pluralidade e pelo constante desejo de modificar a realidade. Assim, é preciso invalidar o olhar de marginalização que ainda é lançado à EJA, pois não mais lhe cabe. São urgentes as discussões e as lutas em prol das políticas públicas educacionais que têm sido vitimadas por ataques constantes de neoconservadores que intencionam destruir qualquer possibilidade de a classe trabalhadora ter acesso ao conhecimento. Por isso se faz necessário romper com tais ataques, que não só nega o direito à educação, mas têm relegado e colaborado para que a EJA volte à margem das modalidades de ensino.

Atualmente há outro fator preocupante quanto ao futuro da educação deste país que se vê diante do cenário de pandemia. Considerando que um dos principais problemas enfrentados hoje na EJA se refere à permanência dos sujeitos na escola, com a suspensão das aulas devido ao distanciamento social, fica a indagação: será que esses educandos vão voltar às suas respectivas instituições de ensino após a pandemia? Não cabe nesta análise apresentar prognósticos, contudo são preocupantes os impactos emocionais e sociais que esse momento pandêmico está causando aos discentes e docentes, levando em conta as possibilidades de evasão e as condições de acesso e permanência dos jovens e adultos na escola no pósisolamento. Todas essas apreensões têm fundamento, pois acarretam na exclusão desses sujeitos, tendo em vista as dificuldades que eles possuem de acesso às Tecnologias de 
Informação e Comunicação (TICs), situação que amplia as desigualdades sociais que, nesse aspecto, vem afetando todo o campo da educação e causando danos.

A educação em tempos de pandemia tem sido impactada de diversas maneiras e de forma globalizada. A alfabetização no Brasil, por si só, é um grande desafio e ganha maiores proporções pela situação de isolamento social, destacando as desigualdades entre os lares brasileiros, nos quais pouco se tem a presença de livros, acesso à tecnologia e pais alfabetizados. Ademais, a educação escolar é um fenômeno que não se dá de forma isolada das relações sociais, da estrutura econômica, política e democrática de uma sociedade, pois está vinculada aos interesses econômicos e ideológicos de grupos e classes sociais.

Conclui-se, assim, que é nítido o distanciamento entre aquilo que é proclamado e o que realmente é efetivado no contexto das políticas públicas educacionais e que a Educação de Jovens e Adultos possui nítidas dificuldades institucionais, sociais e econômicas. Devido à conjuntura atual, as adversidades têm sido agravadas e maiores são as preocupações e as possibilidades de evasão escolar para este grupo, uma vez que a EJA é composta, majoritariamente, por trabalhadores. Tais dificuldades se estendem à formação de professores e, por isso, urge defender uma formação que contemple as particularidades da EJA e que permita pensá-la como área de estudo fundamental nos cursos de formação para a docência, operacionalizando uma constante construção esculpida nas múltiplas possibilidades do "tornarse" humano. Em uma situação em que centenas de jovens vivenciam uma realidade de exclusão, de vulnerabilidade, de desigualdade, se fazem emergentes as ações que promovam transformações.

\section{Referências}

ARROYO, Miguel González. Educação de jovens: adultos: um campo de direitos e de responsabilidade pública. In: SOARES, L. (Org.). Diálogos na educação de jovens e adultos. Belo Horizonte: Autêntica, 2007. p. 19-50.

FONSECA, João José Saraiva da. Metodologia da pesquisa científica. Fortaleza: UEC, 2002.

FREIRE, Paulo. Pedagogia do oprimido. Rio de Janeiro: Paz e Terra, 2017.

GADOTTI, Moacir. Educação de Adultos como Direito Humano. EJA EM DEBATE, Florianópolis, Ano 2, n. 2. Jul. 2013. Disponível em:

$<$ https://periodicos.ifsc.edu.br/index.php/EJA/article/view/1004/pdf>. Acesso em: 16 mar. 2021.

GOIÂNIA. Proposta Político-pedagógica da Educação de Adolescentes, Jovens e Adultos. Goiânia: Secretaria Municipal de Educação e Esporte, 2013. 
LIBÂNEO, José Carlos. O campo do conhecimento pedagógico e a identidade profissional do pedagogo. In: LIBÂNEO, José Carlos. Pedagogia e pedagogos, para quê? 12 ed. São Paulo: Cortez, 2010. p. 25-42.

LIBÂNEO, José Carlos. Adeus professor, adeus professora? Novas exigências educacionais e profissão docente. 5 ed. São Paulo: Cortez, 2001.

PAIVA, Jane. Formação docente para a Educação de Jovens e Adultos: o papel das redes no aprendizado ao longo da vida. Revista da FAEEBA - Educação e Contemporaneidade, Salvador, v. 21, n. 37, p. 83-96, jan./jun. 2012. Disponível em:

$<$ https://www.revistas.uneb.br/index.php/faeeba/article/view/459/399>. Acesso em: 15 mar. 2021.

PAIVA, Vanilda Pereira. Educação popular e educação de jovens e adultos. Rio de Janeiro: Edições Loyola, 1973.

PIMENTA, Selma Garrido; LIMA, Maria Socorro Lucena. Estágio: diferentes concepções. In: _. Estágio e docência. São Paulo: Cortez, 2004. p. 33-57. (Coleção docência em formação. Série saberes pedagógicos).

PUC GOIÁS. Diretrizes do Estágio Supervisionado no Curso de Pedagogia da PUC Goiás. Goiânia: PUC Goiás, 2014.

PUC GOIÁS. Portaria $n .^{\circ} 11 / 2020-G R$. Disponível em:

$<$ https://coronavirus.pucgoias.edu.br/wp-content/uploads/2020/04/Portaria-11_19mar.pdf.> Acesso em: 20 jun. 2020.

ROSA, Carolina Schenatto da. Toda a idade é certa se a educação é ao longo da vida:

horizontes de(s)coloniais para política de educação de jovens e adultos na América Latina. 2017. 139f. Dissertação (Mestrado em Educação) - Programa de Pós-Graduação em Educação, Universidade La Salle, Canoas, 2017. Disponível em:

https://doi.org/10.24115/s2446-6220201621118p.36-50. Acesso em: 01 jun. 2020.

iDecreto sobre suspensão das atividades em Goiás. Disponível em:

<https://www.saude.go.gov.br/files/banner_coronavirus/decreto9637_71-03-2020-DOE.pdf.> Acesso em: 31 mai. 2020. 